\title{
A MÚSICA ENQUANTO INSTRUMENTO DE ABORDAGEM DO PENSAMENTO FILOSÓFICO: UMA EXPERIÊNCIA DE TRABALHO EM ADORNO, HORKHEIMER E ARENDT COM ADOLESCENTES
}

\author{
MUSIC AS A TOOL FOR APPROACHING PHILOSOPHICAL THOUGHT: AN EXPERIMENT IN \\ ADORNO, HORKHEIMER AND ARENDT WITH ADOLESCENTS
}

LA MÚSICA COMO HERRAMIENTA DE APROXIMACIÓN AL PENSAMIENTO FILOSÓFICO: UNA EXPERIENCIA DE TRABAJO SOBRE ADORNO, HORKHEIMER Y ARENDT CON ADOLESCENTS

\author{
Merielle Camilo \\ (iD) 9 \\ Mestrado em Bioenergia \\ (UNICENTRO) \\ Professora da Rede Estadual de \\ Educação do Estado do Paraná \\ (SEED-PR) \\ merielle.camilo@gmail.com
}

\section{Marcos Cesar Danhoni Neves \\ iD 9}

Doutorado em Educação (UNICAMP)

Professor da Universidade Estadual de

Maringá (UEM)

macedane@yahoo.com

\section{Belmiro Marcos Beloni \\ (iD) 9}

Mestre em Geografia (UNICENTRO)

Técnico em Assuntos Educacionais

(UTFPR) e Professor da Rede

Estadual de Educação do Estado do

Paraná (SEED-PR)

belmirobeloni@gmail.com

\author{
Alessandra Dutra \\ (iD) 9 \\ Doutorado em Linguística e Língua \\ Portuguesa (UNESP) \\ Professora da Universidade \\ Tecnológica Federal do Paraná \\ (UTFPR) \\ dutralessandra@gmail.com
}

\begin{abstract}
Resumo
Historicamente, a música é uma construção humana da subjetividade e criatividade dos indivíduos e, ao mesmo tempo, uma construção da identidade de grupo. A música revela ansiedades, modo de ser e desejos de uma sociedade, entre outros. Analisar as letras de músicas é desvendar um universo dentro de uma comunidade em determinado contexto. No presente trabalho, os alunos do terceiro ano do ensino médio foram instigados a analisarem músicas de diversos gêneros musicais, escolhidas a critério deles mesmos, com as temáticas: racismo, xenofobia, homofobia, misoginia e feminicídio. Objetivou-se explicitar as relações entre as letras de músicas conhecidas e como a mensagem reproduzida é introjetada e normalizada pelos ouvintes, não importando o discurso excludente ou opressor destas. Os participantes, após o processo de escolha, puderam discutir os conceitos de indústria cultural, propaganda, cultura de massas (Escola de Frankfurt) e a banalização da maldade (Hannah Arendt), com resultado surpreendente do interesse dos alunos e ampliação de seu senso crítico em relação ao mundo ao seu redor.
\end{abstract}

Palavras-chave: Música. Banalidade do Mal. Indústria Cultural.

Recebido em: 19 de janeiro de 2021.

Aprovado em: 16 de abril de 2021.

Como citar esse artigo (ABNT):

CAMILO, Merielle et al. A música enquanto instrumento de abordagem do pensamento filosófico: uma experiência de trabalho em Adorno, Horkheimer e Arendt com adolescentes.

Revista Prática Docente, v. 6, n. 1, e020, 2021. http://doi.org/10.23926/RPD.2021.v6.n1.e020.id984 


\section{Abstract}

Historically, music is a human construction of subjectivity and creativity of individuals and, as well as a construction of group identity. Music reveals a society's anxieties, way of being and desires, among others. To analyze the lyrics of songs is to unveil a universe within a community in a given context. In the present work, the third year high school students were asked to analyze songs of different musical genres, chosen at their own criteria, with the following themes: racism, xenophobia, homophobia, misogyny, and feminicide. The objective was to make explicit the relationships between the lyrics of well-known songs and how the reproduced message is introjected and normalized by the listeners, regardless of their excluding or oppressive discourse. After the choice process, the participants were able to discuss the concepts of cultural industry, propaganda, mass culture (Frankfurt School) and the banalization of evil (Hannah Arendt), with a surprising result of the students' interest and expansion of their critical sense in relation to the world around them.

Keywords: Music. Banality of Evil. Cultural Industry.

\section{Resumen}

Históricamente, la música es una construcción humana de la subjetividad y la creatividad de los individuos y, al mismo tiempo, una construcción de la identidad del grupo. La música revela las ansiedades, la forma de ser y los deseos de una sociedad, entre otros. Analizar las letras de las canciones es desvelar un universo dentro de una comunidad en un contexto determinado. En el presente trabajo, se instigó a los alumnos de tercero de Bachillerato a analizar canciones de diversos géneros musicales, elegidas a su criterio, con los temas: racismo, xenofobia, homofobia, misoginia y feminicidio. El objetivo era explicar las relaciones entre las letras de canciones conocidas y cómo el mensaje reproducido es introyectado y normalizado por los oyentes, independientemente del discurso excluyente u opresivo de éstas. Los participantes, tras el proceso de elección, pudieron debatir los conceptos de industria cultural, propaganda, cultura de masas (Escuela de Frankfurt) y banalización del mal (Hannah Arendt), con un resultado sorprendente de interés de los alumnos y de ampliación de su sentido crítico en relación con el mundo que les rodea.

Palabras clave: Música. Banalidad del Mal. Industria cultural. 


\section{INTRODUÇÃo}

O trabalho com temas contemporâneos é emergente nas ciências humanas, diante das rápidas mudanças das relações sociais e da própria demanda de que disciplinas com a Filosofia se conecte com a realidade vivienciada por estudantes, ainda mais impreterível no ensino médio, onde se finalizam, muitas vezes, as possibilidades de discussão reflexiva oferecida pela educação básica. Sendo assim, os conteúdos da disciplina, para além de uma linearidade histórica, necessitam de aplicação na sociabilidade e composição do ethos dos educandos. Daí a efetividade do trabalho com a música e as relações travadas com discussão sobre indústria cultural.

A música tem influência direta nas nossas vidas desde a nossa infância, com cantigas de ninar, de roda, em desenhos animados e outras produzidas para o público infantil. Essa influência permanece por toda a vida e, na adolescência, possui um caráter muito forte de identidade de grupo, tornando-se muito importante na exteriorização da personalidade dos adolescentes. Se olharmos os vários estilos entre os adolescentes veremos preferências musicais distintas que fazem parte desse visual, com coreografias específicas decoradas da mesma forma que realizadas na infância quando imitavam uns aos outros. Nessa perspectiva, muitas vezes, as letras das músicas ficam em segundo plano diante da melodia e coreografia, sendo ignoradas parcialmente ou totalmente. Como na infância, muitos jovens repetem os refrões das músicas de forma automática, sem analisar o que dizem.

O perigo dessa forma de repetição de frases sem análise é a perpetuação e disseminação de pensamentos autoritários, fascistas/neonazistas, preconceituosos e cheios de ódio. Passam despercebidos por aqueles que de forma alienada repetem refrãos sem analisá-los apenas por sua melodia, pelo estímulo da mídia e do consumismo.

\footnotetext{
Se a opinião pública atingiu um estado em que o pensamento inevitavelmente se converte em mercadoria e a linguagem em seu encarecimento, então a tentativa de pôr a nu semelhante depravação tem de recusar lealdade às convenções linguísticas e conceituais em vigor, antes que suas consequências para a história universal frustrem completamente essa tentativa (ADORNO; HORKHEIMER, 1947, p.3).
}

A música enquanto fenômeno humano sempre teve o objetivo ampliar o alcance de determinado discurso, seja por meio da melodia e ainda mais pela letra. Sendo que atualmente para além do próprio aúdio, a música comercial infere o vídeo, que preconiza comportamentos e identificação, independemente da idade, sendo com maior força nos jovens, enquanto mercado preferencial da massificação cultural. Tal fenômeno, não pode ser ignorado, pois 
retrata em tempo real os rumos das relações sociais sobre as quais a Filosofia, enquanto disciplina de ensino médio, deve tratar, obrigatoriamente.

Nesta experiência, focou-se nas músicas que podem, em primeira vista, parecer inofensivas, divertidas, porém carregam em si o germe de ideias que promovem a maldade e o ódio entre as pessoas por sua ideologia disseminada exaustivamente pelos meios de comunicação. Levando em conta que os adolescentes carregam junto a si, em sua maioria, dispositivos eletrônicos e fones de ouvido, a música está presente em todo momento, na possível dupla função de formar/alienar e lazer.

Esse processo foi estudado no período da república de Weimar (1919-1933) e no período Nazista (1936-1945) pelos teóricos de Frankfurt (Marcuse, Adorno e Horkheimer), e por Hannah Arendt. Nesse período histórico, houve, durante a República de Weimar, a propagação de ideias antissemitas e xenofóbicas, a justificação à exclusão e perseguição ao outro (no caso judeus, ciganos, comunistas, negros, homossexuais, entre outros), pela mídia que consistia, principalmente, na indústria cinematográfica e musical. O que não podia ser tolerado em uma sociedade democrática e plural foi simplesmente normalizado e padronizado como modo de agir, exterminando a diversidade social e de pensamento. Esse processo gradual ocorrido na República de Weimar teve como combustível o ressentimento existente pelas derrotas bélicas, crise econômica e um sentimento de nacionalismo que aflorava, dando espaço a oportunistas que, com um pouco de retórica e muito ódio em seus discursos, empolgaram a nação utilizando o que de pior cada um tinha dentro de si e, sob uma falsa ideia de progresso da sociedade alemã, levou ao poder Hitler e foi omissa diante do holocausto que se produziu nos campos de morte.

O povo alemão foi mentalmente condicionado por aquilo que a Escola de Frankfurt batizou de Indústria Cultural, a discutir apenas questões direcionadas, que limitavam o saber e instigavam os sentimentos de revolta e rancor, ao mesmo tempo em que a Filosofia, as Ciências, as Artes e o conhecimento, em geral, estavam sob intenso ataque. A censura às obras literárias, que culminou na queima de livros em 1933 na praça Bebelplatz, em Berlim, e a expulsão do país de inúmeros intelectuais, fizeram com que a ignorância se tornasse o status quo daquele povo. Arendt, ao analisar o fenômeno totalitário adverte que:

Será que a natureza da atividade de pensar, o hábito de examinar, refletir sobre qualquer acontecimento, poderia condicionar as pessoas a não fazer o mal? Estará entre os atributos da atividade do pensar, em sua natureza intrínseca, a possibilidade de evitar que se faça o mal? Ou será que podemos detectar uma das expressões do mal, qual seja, o mal banal como fruto do não exercício do pensar? (ARENDT, 2009, p. 19). 
Nos últimos anos, estamos vivendo no Brasil um desmonte da educação, visualizado pelo discurso de ódio e perseguição aos professores, promovido principalmente pelos militantes da "Escola sem partido", religiosos evangélicos e por políticos que acusam os docentes de doutrinação. Marcos Cesar Danhoni Neves é um dos muitos intelectuais que alerta para o avanço das ideias obscurantistas na educação:

Devemos lutar para que o Estado laico se imponha, ou estaremos em terreno fértil para o nascimento de 'madrassas' (escolas fundamentalistas do Islã) cristãs e de um Estado baseado no sectarismo religioso perpetuado pela des-educação de sistemas e livros didáticos (NEVES, 2010, p.325).

Esse pensamento de aversão ao conhecimento científico fez com que um radicalismo dualista se estabelecesse em uma visão do "nós" e do "outro", considerado por Hannah Arendt como um dos elementos originadores do Totalitarismo, ao tornar o que não pensa igual um inimigo. Essa visão estimula um senso comum de opiniões (doxa) que é por vezes é embalada por fake news, por preconceitos e estigmas sociais, pela fé e superficialidade de conhecimento sobre qualquer assunto. "O totalitarismo não procura o domínio despótico dos homens, mas sim um sistema em que os homens sejam supérfluos. "(ARENDT, 2012, p. 605).

A ciência (episteme) se põe como contraponto desse senso comum, e acaba vista como inimiga dessa fé que surge das opiniões que lhes são colocadas como verdades. O resultado são as preocupantes reformas (na verdade, deformas) educacionais que extinguem ou suprimem conteúdos científicos e de humanidades dos currículos, reforçando apenas um enfoque muito básico na formação dos alunos, voltado ao mercado de trabalho.

Esse cenário propicia um ambiente muito semelhante ao período pré-nazista na Alemanha, com polarização partidária extrema e conflitos fabricados. A propagação de fake news é outro fenômeno que escancara a ignorância e o ressentimento crescente da população, que acredita sem verificar a veracidade das informações e facilmente se demonstra manipulável. O perigo que vivemos sob o inflar do ódio e a supressão da racionalidade faz com que o mal se banalize como Arendt alertou, como o "fruto do não exercício do pensar".

$\mathrm{Na}$ sociedade brasileira, o crescente e assustador número de cenas lamentáveis de racismo nas ruas e confrontos motivados por xenofobia, casos diários de feminicídio e homofobia são embalados por fake news, músicas e youtubers que inflam os piores sentimentos nas pessoas, e fazem com que se sintam confortáveis em agir de forma absurdamente maldosa, como se isso fosse um regramento normal ou socialmente aceitável. Nesse cenário é urgente que a escola seja um campo de resistência, a fim de impedir ou frear ações dessa natureza. 


\section{REMOVENDO AS VENDAS: A MALDADE À BRASILEIRA}

No ano de 2019, o Brasil vivenciou um fenômeno muito interessante, seguindo levantamento o Instituto de Pesquisa Econômica e Aplicada (IPEA) no seu Atlas da Violência, o número de homicídios diminuiu em relação a 2018: 22\%, porém, com um aumento significativo das mortes de LGBTQ+, mulheres, pobres e negros. Segundo a pesquisa do IPEA existe também uma preocupação sobre a elevada taxa de mortes entre jovens.

(...) a morte prematura de jovens ( 15 a 29 anos) por homicídio é um fenômeno que tem crescido no Brasil desde a década de 1980", (...) "exatamente no momento em que o país passa pela maior transição demográfica de sua história, rumo ao envelhecimento, o que impõe maior gravidade ao fenômeno (IPEA, p.6, 2019).

Estamos vivenciando um momento no Brasil em que a violência está matando nossa juventude e exterminando nossa diversidade e liberdade, pois:

Para além da questão da juventude, os dados descritos nesse relatório trazem algumas evidências de um processo extremamente preocupante nos últimos anos: o aumento da violência letal contra públicos específicos, incluindo negros, população LGBTI, e mulheres, nos casos de feminicídio" (IPEA, p.6, 2019).

Segundo o estudo do IPEA, "houve um crescimento dos homicídios femininos no Brasil em 2017, com cerca de 13 assassinatos por dia. Ao todo, 4.936 mulheres foram mortas, o maior número registrado desde 2007” (p.35), um aumento considerável, e com um grave problema:

O ponto principal é que não se sabe ao certo se o aumento dos registros de feminicídios pelas polícias reflete efetivamente aumento no número de casos, ou diminuição da subnotificação, uma vez que a Lei do Feminicídio (Lei no 13.104, de 09/03/2015) é relativamente nova, de modo que pode haver processo de aprendizado em curso pelas autoridades judiciárias (IPEA, p.39).

Esse fato preocupante levantado pelos pesquisadores vem reafirmar, apenas, o inconsciente coletivo de um país que ainda considera naturais os chamados "crimes de honra ou passionais", propagados pela cultura machista de inferiorização da mulher, objetificação do seu corpo e apropriação de sua vida e liberdade. A normalização do comportamento dominador e passional do homem como ideal de virilidade, e a culpabilização expositiva da vítima tem sido um modus operandi da sociedade brasileira, e de sua imprensa que lucra com histórias de tragédias urbanas.

Sobre a população negra, o estudo do IPEA aponta que:

(...) enquanto a taxa de homicídios de mulheres não negras teve crescimento de $1,6 \%$ entre 2007 e 2017, a taxa de homicídios de mulheres negras cresceu 29,9\%. Em números absolutos, a diferença é ainda mais brutal, já que entre não negras o crescimento é de $1,7 \%$ e entre mulheres negras de $60,5 \%$ ", revelando "a enorme dificuldade que o Estado brasileiro tem de garantir a universalidade de suas políticas públicas (IPEA, p.39-40). 
O número de negros vítimas da violência no Brasil é alarmante. A visão racista do brasileiro, mesmo que negada pela população, contribui muito para o aumento da desigualdade social e marginalização do negro, visto como um incapaz, marginal e ameaça à sociedade, o que contribui muito para políticas que acabam incentivando o extermínio de jovens negros em comunidades carentes durante operações policiais com a "justificativa" de combate ao crime. Aqui deixamos claro que é essencial a ação das forças policiais no combate ao crime, porém, é impossível não atentar aos índices explosivos de jovens mortos durante esses "confrontos" ou abordagens. A militarização das forças de segurança está na raiz dessa política de extermínio, entendida como uma força que protege tão somente as elites do país.

Sobre as comunidades LGBTQ+ o estudo, de forma inédita, abordou essa população utilizando-se também das pesquisas e "relatórios do Grupo Gay da Bahia (GGB), que há 39 anos vem fazendo um levantamento do número de pessoas assassinadas por questões homofóbicas, com base em notícias publicadas na imprensa, na internet e informações pessoais" (IPEA, p.56), denunciando, assim, a invisibilidade e dificuldade de informações sobre essa parcela da população. Segundo os estudos, o ano com mais denúncias no Disque100 foi o de 2012. A partir desse ano, houve redução e um novo aumento no número de denúncias de homofobia, porém, como no que já abordamos sobre a questão da violência contra a mulher, isso pode ser decorrência da diminuição da subnotificação por parte das autoridades policiais e leis que criminalizam a homofobia que encontram-se em discussão no país há alguns anos (em 13 de junho de 2019 foi julgada como crime pelo STF em resposta à PL 5003/2001).

O estudo, entretanto, também revela o aumento de mais de $15 \%$ nos casos de violência sem resultar em mortes (p.64), caracterizando um movimento crescente de homofobia no país. Segundo noticiários, o Brasil teve, em 2017, o número alarmante de 445 casos de homossexuais mortos, como revela o levantamento do Grupo Gay da Bahia, e de acordo com a ONG Transgender Europe. Entre 2008 e junho de 2016, o Brasil contabilizou 868 travestis e transexuais que perderam a vida de forma violenta. Com esses dados, o Brasil lidera o ranking dos países que mais matam homossexuais. Isso demonstra a ineficácia das políticas públicas e a necessidade de ações para o exercício da tolerância, do respeito e da valorização da diversidade em nosso país em tentativa a frear os movimentos de extermínio dessas populações.

Outra população marginalizada e com altos índices de violência e cenas absurdas de preconceito é a de estrangeiros refugiados em nosso país. 
um total de 1.086 refugiados de diversas nacionalidades. Com isso, o país atinge a marca de 11.231 pessoas reconhecidas como refugiadas pelo Estado brasileiro (ACNUR, 2018).

Existem muitos relatos de trabalho escravo dessas populações quando entram ilegalmente no país, de conflitos nas fronteiras norte do país com o impedimento por parte da população brasileira do ingresso de venezuelanos em nosso território, de forma violenta, e casos públicos de agressão xenofóbica em diversas cidades do país, motivados por discursos de que estariam roubando o emprego da população local.

No entanto, não é preciso recorrer aos índices do IPEA para percebermos a crescente violência contra as populações jovens, de periferia, negros, homossexuais, mulheres e crianças. Quando observamos os noticiários, são diárias as manchetes envolvendo mortes violentas, que se "justificam" com as afirmativas mais banais e risíveis por parte dos agressores e, por outro lado, assistimos à morosidade da justiça brasileira e penas ineficazes, quando ocorrem. Apenas analisando a realidade local de Guarapuava- PR, onde se encontra o público alvo desse trabalho, nota-se diversas manchetes sobre feminicídios, tendo o caso da Sra. Tatiane Spitzner ${ }^{1}$ com repercussão nacional, assassinatos ou espancamentos de LGBTQ+, e discursos em comentários de redes sociais com alto teor de ódio. Nesse cenário, um trabalho que estimule a reflexão da juventude é essencial.

\section{DESENVOLVIMENTO: DA TEORIA À REALIDADE}

Como parte da disciplina de Filosofia no Ensino Médio, conforme as Diretrizes e Bases da Educação Nacional (Lei no 9.394/96) e os Referenciais Curriculares do Paraná (BNCC), a disciplina deve abranger discussões sobre o exercício da cidadania, e na grade curricular proposta pelo governo do Paraná está o conteúdo de Filosofia da Arte a ser trabalhado no último ano da formação básica dos alunos.

A Filosofia da Arte, também chamada de Estética, contempla o estudo das manifestações artísticas do ser humano como forma de exteriorizar seu pensamento, ideias e desejos em várias fases da história humana. Desde a ideia de belo em Platão e Kant é abordado o conceito de arte em Aristóteles, Martin Hegel, Gilles Deleuze, Frederich Nietzsche, entre

\footnotetext{
1 Tatiane Spitzner morreu após violência doméstica, gravada por câmeras de segurança, de elevadores e estacionamento, e segundo analise pericial do IML, estrangulada e jogada do $4^{\circ}$ andar do prédio em que vivia em Guarapuava-Pr com Luís Felipe Manvailer, no dia 22 de julho de 2018. O prédio em que os fatos ocorreram fica uma quadra do colégio onde as atividades relatadas nesse trabalho. O caso irá a Juri popular. Manvailer alega inocência, porém após os fatos ele tentou esconder no apartamento o corpo de Tatiane, alterar a cena do crime limpando marcas de sangue, e fugiu com o carro da vítima sentido Paraguai, sendo preso após envolver-se em um acidente de trânsito.
} 
outros. As manifestações contemporâneas de arte também são consideradas quando se fundem com o estudado em Filosofia Política (Karl Marx, Hannah Arendt, Angela Davis, Michael Foucault, Noan Chomsky) na abordagem sobre mídias (televisão, cinema, música, teatro, literatura, arte moderna, etc.), por meio de teóricos como os da Escola de Frankfurt (principalmente Theodor Adorno e Marx Horkheimer).

Depois de discutirmos as principais ideias teóricas sobre a Filosofia da Arte e, principalmente, da Escola de Frankfurt e de como o Nazismo se apropriou dos meios de comunicação de forma irreversível para disseminação de ideologias em massa, e tendo recentemente em Filosofia Política trabalhado os conceitos de Hannah Arendt com artigos selecionados onde os alunos já tiveram um contato com a atualidade da obra da autora, é chegado o momento de unir a teoria à prática. Os alunos assistiram ao documentário "Mulheres brasileiras: do ícone midiático à realidade" produzido pelas organizações Paz com Dignidad e Revista Pueblos. O vídeo traz entrevistas com Terezinha Vicente e Rita Freire, da Rede Mulher e Mídia; Jacira Melo, diretora do Instituto Patrícia Galvão; Iris Miranda, psicóloga e ativista e Melissa Miranda, jornalista e ativista, e mostra como os padrões de beleza são direcionados e estereótipos reforçados. A partir dos conceitos explicitados na publicidade como fonte de propagação de ideias que muitas vezes deveriam ser combatidas e não banalizadas, os alunos dos Colégios Estaduais Visconde de Guarapuava e Rui Barbosa foram desafiados a realizar as análises das músicas que ouvem.

Para o sucesso da proposta, torna-se elementar uma abordagem qualitativa, já que se pode entender que eventos e interações são significantes para as pessoas em um contexto específico, destacando os valores, crenças, expressões, opiniões e atitudes em uma determinada situação e contexto histórico e social. As pessoas não são reduzidas a números, estatísticas ou hipóteses, mas como um todo, são consideradas em seu ambiente natural (Nunam, 1992). Conforme sugerido por Munby (1984) e Barcelos (2001), o estudo das reflexões devem incluir fatores como a formação social e cultural dos alunos, bem como da relação entre o discurso (letra) e aquilo que se acredita, bem como das possíveis metáforas usadas.

A ideia do presente trabalho foi inspirada em uma exposição "Música: Uma Construção de Gênero", que aconteceu em São Leopoldo - RS, em 2018, como parte das atividades do Dia Internacional da Mulher, idealizada pela Secretaria de Políticas para Mulheres (SEPOM), e teve como objetivo fazer um alerta a respeito de músicas de conteúdo machista veiculadas pela mídia. Ampliando essa ideia, foram divididos grupos na sala e sorteado os seguintes temas: 
Feminicídio e violência contra a mulher, Homofobia, Xenofobia e Racismo. Os alunos tiveram o objetivo de dentro da temática sorteada buscar músicas que promovessem a conscientização ou o preconceito/violência, e relacioná-las com os teóricos de Frankfurt e com Hannah Arendt. Após a pesquisa das músicas e análise filosófica, os estudantes produziram cartazes com o tema "você presta atenção no que ouve?", com as suas considerações e os trechos das músicas. Essa produção artística ficou exposta nos corredores do Colégios após apresentação para os colegas da turma.

\section{Resultados e Discussão}

As apresentações de trabalhos realizados pelos alunos ocorreram no mês de outubro de 2019 e surpreenderam pelo interesse dos alunos em buscarem as músicas e no esforço para relacionarem as letras à dados estatísticos e notícias para respaldar a análise filosófica (Figura 1).

Dentre as músicas escolhidas livremente por eles houve a escolha de vários gêneros musicais, do funk ao sertanejo, mostrando também os diversos grupos e estilos existentes dentro de uma sala de aula, e dando liberdade de mostrarem suas individualidades e pensamentos. Das músicas escolhidas, a análise que se repetiu nas turmas foi da música "Rosas" do grupo musical "Atitude feminina", que conta uma história de amor que termina em violência doméstica e feminicídio, mostrando como é naturalizada a violência e com uma mensagem relatando que a cada 15 segundos uma mulher é agredida no Brasil por maridos ou namorados. Houve também alusão às músicas de Bezerra da Silva, "Piranha", Grupo gauchesco Tradição, "Ajoelha e chora", e a de Sidney Magal, "Se te pego com outro" (figura 3), todas com contexto de dominação masculina, violência doméstica e referência à impunidade nos casos de feminicídios.

Sobre a temática da homofobia, a música "Indestrutível”, de Plabo Vitar, foi apresentada por mais que um grupo de alunos. A música relata o bullying sofrido por pessoas LGBTQ+, os perigos existentes, o processo de aceitação das famílias, além de ser um desabafo do próprio artista em relação à sua própria história e seu processo de superação até o sucesso. A discussão e a sensibilização percebidas no clipe e música foram muito interessantes, e serviram de alento os alunos que expuseram também suas dificuldades em uma sociedade homofóbica. Outra música nessa temática foi a do grupo Mamonas Assassinas, "Robocop gay", que foi sucesso nos anos 90. A discussão foi muito interessante, pois analisou-se um retrocesso na sociedade, uma vez que a letra fala sobre a aceitação do homossexual de forma cômica, o que hoje seria 
considerado por alguns grupos como provocação. Nessa discussão foram abordados figurinos de show usados por Ney Matogrosso e grupos internacionais como Queen que hoje em dia não são mais vistos, devido ao pensamento "conservador" e preconceituoso. A música "Same Love" de Macklemore \& Ryan Lewis (Figura 2) foi analisada também: os alunos trouxeram a música traduzida para o português e o clip legendado para apresentar em sala, assim como "Rock das Aranhas" de Raul Seixas e "Vale Tudo" de Tim Maia (figura 3), que notavelmente possuíam conteúdo lesbofóbico e homofóbico.

Na temática sobre o racismo, a música mais escolhida foi a de Djonga, "Olho de Tigre", também conhecida pelo seu refrão "fogo nos racistas". A música retrata situações de preconceito que uma pessoa negra enfrenta, a revolta desta com o racismo, e refere-se a fatos recentes da mídia brasileira. Durante as discussões vários relatos de alunos sobre situações constrangedoras foram compartilhados, e variaram desde piadas, perseguição de vendedoras ou seguranças em lojas, até ofensas raciais (Figura 3).

Figura 1 - Apresentação de reportagens pesquisadas por estudantes que se relacionam ao tema da pesquisa (feminicídio e violência contra a mulher)

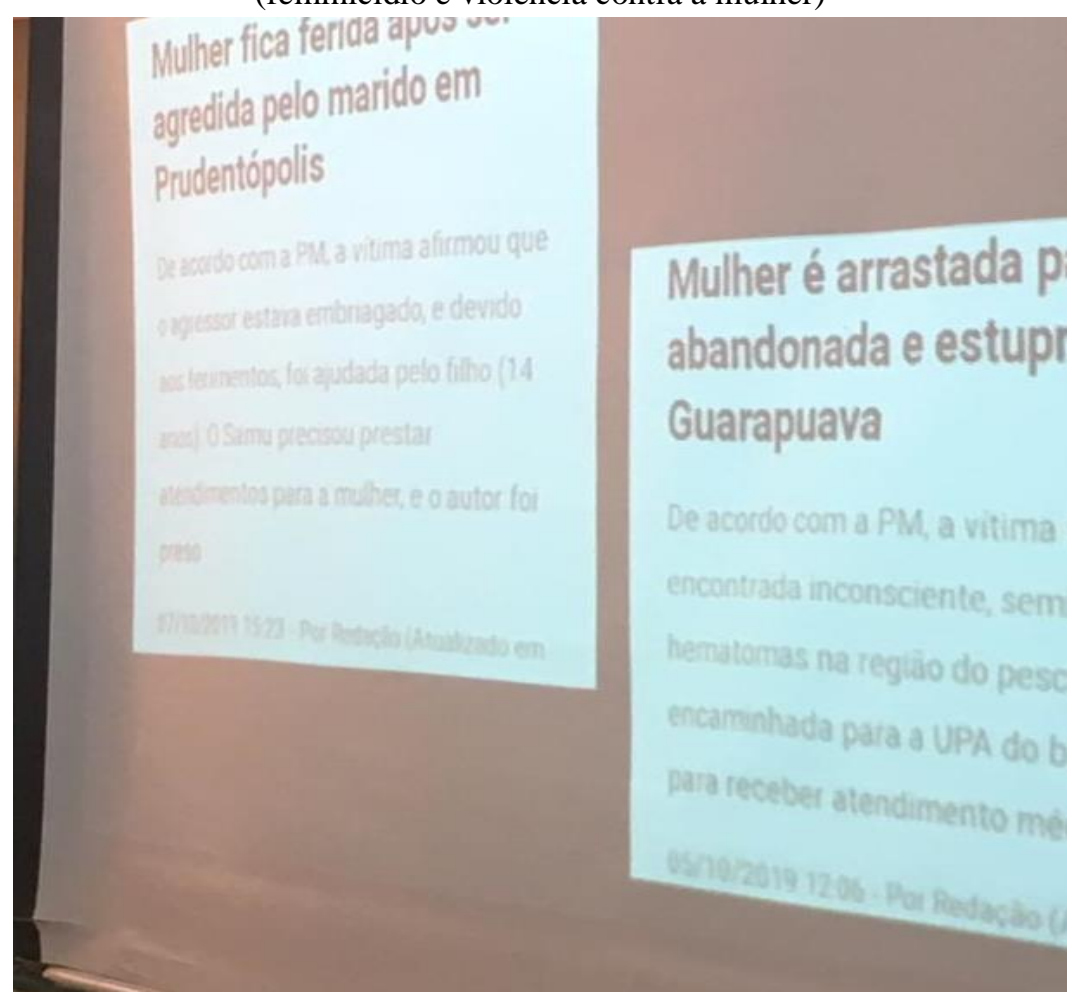


Figura 2 - Cartazes confeccionados em exposição

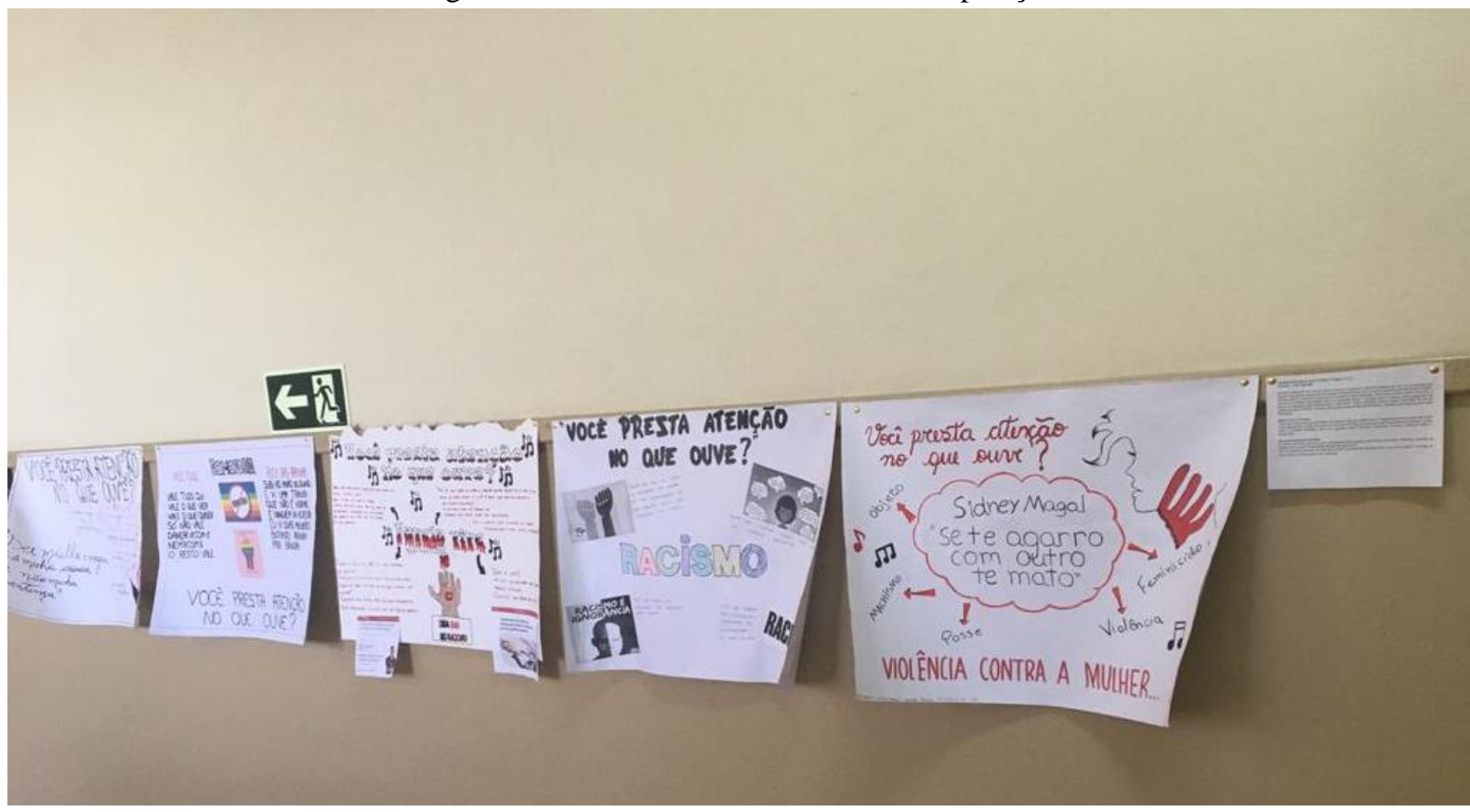

Figura 3 - Cartazes confeccionados pelos alunos durante a atividade

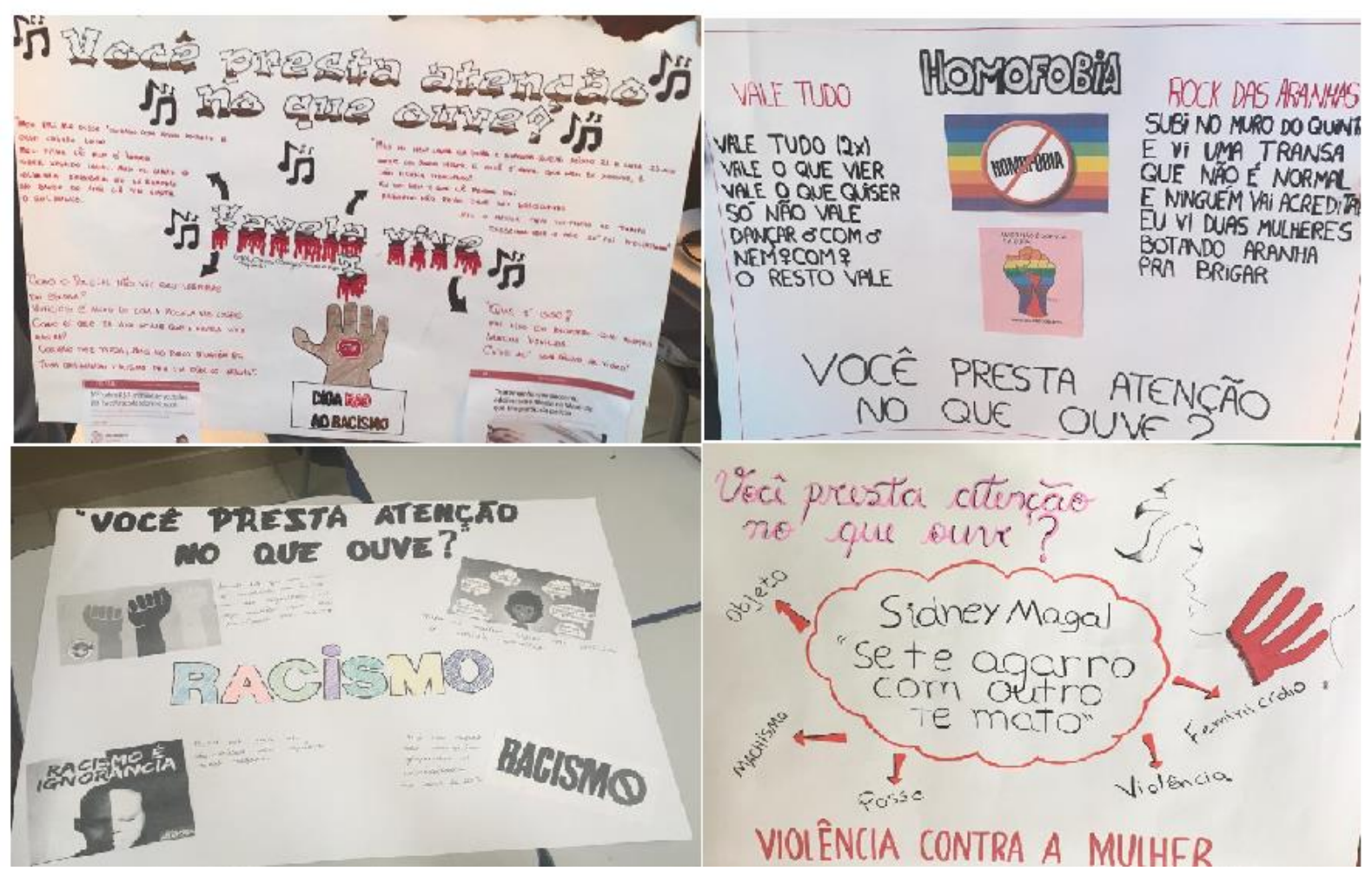

Sobre a temática xenofobia, os alunos tiveram dificuldade de buscar músicas e se limitaram àquela que foi tema recente da novela da Globo "Filhos da Terra", do grupo Tribalistas, "Diáspora”, e fundamentaram suas apresentações com as notícias de xenofobia que ocorreram recentemente em Pacaraima, no estado de Roraima, com relatos de alunos estrangeiros (Colômbia) e as dificuldades de adaptação no Brasil, bem como de alunos que são 
de outras regiões do país: Rio Grande do Sul e Amazonas, devido ao bullying que sofreram por causa do sotaque.

\section{CONSIDERAÇÕES FINAIS}

Trabalhos que instigam a juventude e levam à reflexão sobre o que ouve e observar, de forma crítica, o mundo ao redor, são essenciais para que ocorram mudanças na sociedade, promovendo a tolerância e o respeito, em combate às práticas obsoletas, retrógradas e violentas de machismo. Tais práticas que levam à violência doméstica e ao feminicídio, a homofobia que mata, a xenofobia que exclui e violenta pessoas em situação já vulnerável num país estranho e por razões como pobreza, guerra e perseguições e, finalmente, o racismo, infelizmente persistente em nossa sociedade miscigenada e plural.

Sem a conscientização e sensibilização humana proporcionada pela reflexão crítica e filosófica da realidade e da resistência da escola às levas repressoras, fundamentalistas, que se espalham pelo país reprimindo a liberdade de docência, corremos o risco de ter uma sociedade fadada a repetir os erros do passado, limitada em sua ignorância e manipulados por pessoas que apenas desejam poder sob uma população amedrontada por fake news e cega por uma obediência sem crítica. Não podemos permitir que o conhecimento e a discussão crítica sejam limitados ao ódio e ao preconceito. Cabe à escola, como espaço de discussão, de transformação e reflexão, dar asas, sonhos e esperança de uma sociedade melhor, humana, pacífica e altruísta.

A integralização de uma experiência concreta de discussão reflexiva sobre a música e sua intencionalidade implícita ou explícita, proporciona ao ensino de Filosofia condições de ressaltar sua importância na formação de estudantes do ensino médio. Tratando-se de uma disciplina presente enquanto obrigatória há cerca de duas décadas no currículo da educação básica, sua reconfiguração metodológica é inadiavelmente necessária, para que não seja monolítica e enfadonha. O diálogo interdisciplinar e metodológico, pode e deve recolocar o conhecimento elaborado, enquanto possibilidade de autonomia de pensamento e posicionamento cidadão, frente ao determinismo massificante e fragmentário da sociedade informacional homogeneizadora.

\section{REFERÊNCIAS}

AGÊNCIA DA ONU PARA REFUGIADOS. Dados sobre refúgio no Brasil. Cômite Nacional para os Refugiados (CONARE), 2018. 
ADORNO, Theodor Ludwig Wiesengrund; HORKHEIMER, Max. Dialética do esclarecimento: fragmentos filosóficos (Dialektik der Aufklärung - Philosophische Fragmente). - 1947.

ARENDT, Hannah. A vida do espírito. Rio de Janeiro (RJ): Civilização Brasileira: 2009.

ARENDT, Hannah. Homens em tempos sombrios. São Paulo: Companhia de Bolso; 2008.

ARENDT, Hannah.. Eichmann em Jerusalém: um relato sobre a banalidade do mal. São Paulo: Companhia das Letras; 1999.

BARCELOS, Ana Maria Ferreira. Metodologia de pesquisa das crenças sobre aprendizagem de línguas: estado da arte. Revista Brasileira de Linguística Aplicada, v. 1, n. 1, p. 71-92, 2001.

BORTONI, Larissa. Brasil é o país onde mais se assassina homossexuais no mundo. Radio Senado. Disponível em: https://www12.senado.leg.br/radio/1/noticia/brasil-e-o-pais-quemais-mata-homossexuais-no-mundo acesso em 24/12/2020 às 16:00

Documentário: Mulheres brasileiras: do ícone midiático à realidade. Disponível em: https://www.youtube.com/watch?v=WdWjKBzCWO8

NOVAES, Adriana Carvalho. Pensar sem apoios: Hannah Arendt e a vida do espírito como política do pensar. 2017. Tese de Doutorado - Universidade de São Paulo (USP). Faculdade de Filosofia, Letras e Ciências Humanas São Paulo.

MOREIRA, Rômulo de Andrade. Atlas da Violência no Brasil - 2019. Disponível em http://www.justificando.com/2019/06/12/atlas-da-violencia-no-brasil-2019/ acesso em $24 / 11 / 2020$ às $14: 52$

INSTITUTO DE PESQUISA ECONÔMICA APLICADA. Atlas da Violência 2019. Brasília: Rio de Janeiro: São Paulo: Instituto de Pesquisa Econômica Aplicada; Fórum Brasileiro de Segurança Pública. ISBN 978-85-67450-14-8. Disponível em: http://www.ipea.gov.br/atlasviolencia/download/19/atlas-da-violencia-2019. Acesso em 14/12/2020 às 15:00

MINISTÉRIO DA EDUCAÇÃO. Filosofia e Sociologia no Ensino Médio. Disponível em http://portal.mec.gov.br/pet/323-secretarias-112877938/orgaos-vinculados-82187207/12768filosofia-e-sociologia-no-ensino-medio-sp-1870990710

MORAIS, Gustavo. Exposição denuncia machismo em letras da música brasileira. Cifraclubnews. Disponível em: https://www.cifraclubnews.com.br/noticias/137163exposicao-denuncia-machismo-em-letras-da-musica-brasileira-veja-fotos.html

MUNBY, Hugh. A qualitative approach study of a teacher's beliefs'. Journal of Research in Science Teaching, v. 21, n. 1, p. 27-38, 1984.

NEVES, Marcos Cesar Danhoni. SILVA, Josie Agatha Parrilha da. (Org). Evoluções e Revoluções: o mundo em transição. $2^{\mathrm{a}}$ edição. Maringá: Massoni, 2010. 
NÚCLEO REGIONAL DE EDUCAÇÃO DE GUARAPUAVA. Filosofia da Arte e da Política: uma atividade dos alunos das $3^{\text {a }}$ Séries, do Ensino Médio, do C.E. Visconde de Guarapuava. Disponível em:

http://www.nre.seed.pr.gov.br/modules/noticias/article.php?storyid=19809

NUNAN, David. Research methods in language learning. Cambridge: Cambridge University Press, 1992.

SIQUEIRA, José Eduardo de. Irreflexão e a banalidade do mal no pensamento de Hannah Arendt. Revista Bioetikos- Centro Universitário São Camilo - 2011;5(4):392-400 